\title{
Solubility of Budesonide, Hydrocortisone, and Prednisolone in Ethanol + Water Mixtures at 298.2 K
}

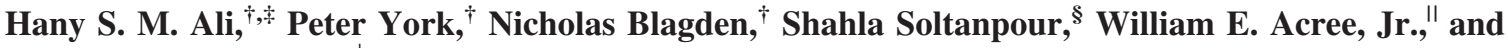 \\ Abolghasem Jouyban*, ${ }^{*}$
}

Institute of Pharmaceutical Innovation, University of Bradford, Richmond Rd., Bradford, BD7 1DP, U.K., Department of Pharmaceutics, Pharmacy Faculty, Assiut University, Assiut 71515, Egypt, Biotechnology Research Center and Pharmacy Faculty and Drug Applied Research Center, Tabriz University of Medical Sciences, Tabriz 51664, Iran, and Department of Chemistry, University of North Texas, Denton, Texas 76203-5070

\begin{abstract}
Experimental solubilities of budesonide, hydrocortisone, and prednisolone in ethanol + water mixtures at 298.2 $\mathrm{K}$ are reported. The solubility of drugs was increased with the addition of ethanol and reached the maximum values of the volume fractions of $90 \%, 80 \%$, and $80 \%$ of ethanol. The Jouyban-Acree model was used to fit the experimental data, and the solubilities were reproduced using previously trained versions of the Jouyban-Acree model and the solubility data in monosolvents in which the overall mean relative deviations (OMRDs) of the models were $5.1 \%, 6.4 \%, 37.7 \%$, and $35.9 \%$, respectively, for the fitted model, the trained version for ethanol + water mixtures, and generally trained versions for various organic solvents + water mixtures. Solubilities were also predicted by a previously established log-linear model of Yalkowsky with the OMRD of $53.8 \%$.
\end{abstract}

\section{Introduction}

The solubility of drugs in ethanol + water mixtures is essential preformulation information. The data could be used in recrystallization and also in formulation processes. The concentration of ethanol in pharmaceutical preparations should be kept as low as possible. The method used to optimize the solvent composition of solvent mixtures for dissolving a desired amount of a drug in a given volume of the solution is the trial and error approach which is time-consuming and expensive. The available solubility data of pharmaceutical compounds in water + cosolvent mixtures are available as comprehensive databases. ${ }^{1}$ Moreover, in the early stages of drug discovery processes, the scarcity of the available amount of a drug/drug candidate is another limiting factor. To address this issue, a number of mathematical models have been presented for predicting the solubility of drugs in water-cosolvent mixtures. These models and their advantages and limitations were recently reviewed. ${ }^{2}$

Of the numerous models developed in recent years, the Jouyban-Acree model is perhaps one of the most versatile models. The model provides very accurate mathematical descriptions for how the solute solubility varies with both temperature and solvent composition. The model is

$$
\begin{aligned}
\log C_{m, T}^{\mathrm{Sat}}=\varphi_{1} \log C_{1, T}^{\mathrm{Sat}}+\varphi_{2} \log C_{2, T}^{\mathrm{Sat}}+ & \\
& \frac{\varphi_{1} \varphi_{2}}{T} \sum_{i=0}^{2} J_{i}\left(\varphi_{1}-\varphi_{2}\right)^{i}
\end{aligned}
$$

where $C_{m, T}^{\text {Sat }}$ is the solute $\left(\mathrm{mol} \cdot \mathrm{L}^{-1}\right)$ solubility in the binary solvent mixtures at temperature $T / \mathrm{K}, \varphi_{1}$ and $\varphi_{2}$ are the volume fractions

\footnotetext{
* To whom correspondence should be addressed. E-mail: ajouyban@ hotmail.com. Fax: +98 4113363231 .

University of Bradford.

Assiut University.

§ Biotechnology Research Center, Tabriz University.

"University of North Texas.

${ }^{\perp}$ Pharmacy Faculty and Drug Applied Research Center, Tabriz University.
}

of the solvents 1 (ethanol) and 2 (water) in the absence of the solute, $C_{1, T}^{\text {Sat }}$ and $C_{2, T}^{\text {Sat }}$ denote the $\mathrm{mol} \cdot \mathrm{L}^{-1}$ solubility of the solute in the neat solvents 1 and 2, respectively, and $J_{i}$ are the constants of the model representing two-body and three-body interactions in the solution ${ }^{3}$ and computed by regressing $\log C_{m, T}^{\mathrm{Sat}}-\varphi_{1}$ $\log C_{1, T}^{\text {Sat }}-\varphi_{2} \log C_{2, T}^{\text {Sat }}$ against $\left(\varphi_{1} \varphi_{2}\right) /(T),\left(\varphi_{1} \varphi_{2}\left(\varphi_{1}-\varphi_{2}\right)\right) /(T)$, and $\left(\varphi_{1} \varphi_{2}\left(\varphi_{1}-\varphi_{2}\right)^{2}\right) /(T){ }^{2}$ Since $\varphi_{1}, \varphi_{2}, \log C_{1, T}^{\text {Sat }}$, and $\log C_{2, T}^{\text {Sat }}$ are dimensionless parameters and $T$ is the only variable with the unit of $\mathrm{K}$, therefore the $J_{i}$ terms should take the unit of $\mathrm{K}^{-1}$. The existence of these model constants which require a number of solubility data in water-cosolvent mixtures for the training process is a limitation for the model when the solubility predictions are the goal of the computations in early drug discovery studies. This version of the model could be considered as a local model, since it is valid only for one drug dissolved in ethanol + water mixtures. This limitation could be resolved using a trained version of the model for a given water-cosolvent mixture. The trained version of the Jouyban-Acree model for the prediction of drug solubility in ethanol + water mixtures at temperature $(T)$ is $^{4}$

$$
\begin{array}{r}
\log C_{m, T}^{\mathrm{Sat}}=\varphi_{1} \log C_{1, T}^{\mathrm{Sat}}+\varphi_{2} \log C_{2, T}^{\mathrm{Sat}}+\frac{724.21 \varphi_{1} \varphi_{2}}{T}+ \\
\frac{485.17 \varphi_{1} \varphi_{2}\left(\varphi_{1}-\varphi_{2}\right)}{T}+\frac{194.21 \varphi_{1} \varphi_{2}\left(\varphi_{1}-\varphi_{2}\right)^{2}}{T}
\end{array}
$$

Equation 2 was trained using 26 different drugs dissolved in ethanol + water mixtures ${ }^{4}$ and further tested on the solubility prediction of clonazepam, diazepam, and lamotrigine at 298.2 $\mathrm{K}$ with the prediction error of $22.3 \%,{ }^{5}$ ethyl maltol at 298.15 $\mathrm{K}$ to $333.15 \mathrm{~K}$ with the prediction error of $23.9 \%{ }^{6}$ and chlordiazepoxide, diazepam, and lorazepam at $303.2 \mathrm{~K}$ with the prediction error of $21.9 \%{ }^{7}$ Equation 2 could be considered as a global model for the solubility of drugs in ethanol + water mixtures at various temperatures. It is only applicable for the solubility prediction of drugs in ethanol + water mixtures, and the effect of drug structures on the solubility was ignored. To 
provide a more general model (i.e., universal model) and also to consider the chemical structure of the drugs, the quantitative structure property relationship (QSPR) models for computing the constants of the Jouyban-Acree model ( $J_{i}$ terms) using Abraham solvation parameters (both for solvents and drugs) were reported as ${ }^{8}$

$$
\begin{gathered}
\log C_{m, T}^{\mathrm{Sat}}=\varphi_{1} \log C_{1, T}^{\mathrm{Sat}}+\varphi_{2} \log C_{2, T}^{\mathrm{Sat}}+ \\
\left(\frac{\varphi_{1} \varphi_{2}}{T}\right)\left\{2113.12-1093.78\left(c_{1}-c_{2}\right)^{2}+\right. \\
3380.66 E\left(e_{1}-e_{2}\right)^{2}-13.87 S\left(s_{1}-s_{2}\right)^{2}- \\
\left.4.92 A\left(a_{1}-a_{2}\right)^{2}-5.66 B\left(b_{1}-b_{2}\right)^{2}+15.25 V\left(v_{1}-v_{2}\right)^{2}\right\}+ \\
\left(\frac{\varphi_{1} \varphi_{2}\left(\varphi_{1}-\varphi_{2}\right)}{T}\right)\left\{-2001.56+1142.78\left(c_{1}-c_{2}\right)^{2}-\right. \\
\left.13.18 A\left(a_{1}-a_{2}\right)^{2}+0.81 B\left(b_{1}-b_{2}\right)^{2}+38.51 V\left(v_{1}-v_{2}\right)^{2}\right\}+ \\
\left(\frac{\varphi_{1} \varphi_{2}\left(\varphi_{1}-\varphi_{2}\right)^{2}}{T}\right)\left\{1474.96-1507.48\left(c_{1}-c_{2}\right)^{2}+\right. \\
4421.30 E\left(e_{1}-e_{2}\right)^{2}+17.98 S\left(s_{1}-s_{2}\right)^{2}-21.20 A\left(a_{1}-a_{2}\right)^{2}+ \\
\left.6.60 B\left(b_{1}-b_{2}\right)^{2}-13.39 V\left(v_{1}-v_{2}\right)^{2}\right\}
\end{gathered}
$$

where $c, e, s, a, b, v, E, S, A, B$, and $V$ are the solvent coefficients and solute Abraham parameters ${ }^{8}$ and subscripts 1 and 2 denote cosolvent and water. The numerical values of Abraham solute parameters of the drugs (computed by PharmaAlgorithm ${ }^{9}$ ), their experimental values, and the Abraham solvent coefficients ${ }^{10}$ employed in this work are listed in Tables 1 and 2, respectively. These terms represent various chemical interactions in the solution. $^{8}$

Equation 3 has been developed employing the experimental Abraham solute parameters, and these parameters are not available for most drugs and also for the drug candidates. In another investigation, the computed solute parameters were employed to train a universal cosolvency model as ${ }^{11}$

$$
\begin{gathered}
\log C_{m, T}^{\mathrm{Sat}}=\varphi_{1} \log C_{1, T}^{\mathrm{Sat}}+\varphi_{2} \log C_{2, T}^{\mathrm{Sat}}+ \\
\left(\frac{\varphi_{1} \varphi_{2}}{T}\right)\left\{1639.07-561.01\left[\left(c_{1}-c_{2}\right)^{2}\right]-\right. \\
1344.81\left[E\left(e_{1}-e_{2}\right)^{2}\right]-18.22\left[S\left(s_{1}-s_{2}\right)^{2}\right]- \\
3.65\left[A\left(a_{1}-a_{2}\right)^{2}\right]+0.86\left[B\left(b_{1}-b_{2}\right)^{2}\right]+ \\
\left.4.40\left[V\left(v_{1}-v_{2}\right)^{2}\right]\right\}+\left(\frac{\varphi_{1} \varphi_{2}\left(\varphi_{1}-\varphi_{2}\right)}{T}\right)\{-1054.03+ \\
1043.54\left[\left(c_{1}-c_{2}\right)^{2}\right]+359.47\left[E\left(e_{1}-e_{2}\right)^{2}\right]- \\
1.20\left[S\left(s_{1}-s_{2}\right)^{2}\right]+30.26\left[A\left(a_{1}-a_{2}\right)^{2}\right]- \\
\left.2.66\left[B\left(b_{1}-b_{2}\right)^{2}\right]-0.16\left[V\left(v_{1}-v_{2}\right)^{2}\right]\right\}+ \\
\left(\frac{\varphi_{1} \varphi_{2}\left(\varphi_{1}-\varphi_{2}\right)^{2}}{T}\right)\left\{2895.07-1913.07\left[\left(c_{1}-c_{2}\right)^{2}\right]-\right. \\
901.29\left[E\left(e_{1}-e_{2}\right)^{2}\right]-10.87\left[S\left(s_{1}-s_{2}\right)^{2}\right]+ \\
\left.24.62\left[A\left(a_{1}-a_{2}\right)^{2}\right]+9.79\left[B\left(b_{1}-b_{2}\right)^{2}\right]-24.38\left[V\left(v_{1}-v_{2}\right)^{2}\right]\right\}
\end{gathered}
$$

Equation 4 was tested on 152 solubility data sets of various drugs in eight cosolvents, and the produced prediction uncertainty was $42.4 \pm 59.5 \%$. $^{11}$

The alternative prediction method is the trained version of the $\log$-linear model of Yalkowsky and Roseman ${ }^{12}$ which is expressed by

$$
\log C_{m, T}^{\mathrm{Sat}}=\log C_{2, T}^{\mathrm{Sat}}+(0.309+0.945 \log P) \varphi_{1}
$$

where $\log P$ is the $\log$ arithm of the drug's partition coefficient. ${ }^{13}$ The experimentally obtained values of $\log P$ for budesonide, hydrocortisone, and prednisolone employed in this work were $3.21,{ }^{14} 1.61,{ }^{15}$ and $1.62,{ }^{15}$ respectively.

Hagen and Flynn ${ }^{16}$ reported the $\mathrm{mol} \cdot \mathrm{L}^{-1}$ and mol fraction solubilities of hydrocortisone in a number of organic solvents and also in binary mixtures of propylene glycol + water at $25^{\circ} \mathrm{C}$. The reported equilibration times for all investigated solvents (except for propylene glycol and the binary mixtures with higher propylene glycol concentrations) were less than $24 \mathrm{~h}$. In another investigation, ${ }^{17}$ different aqueous solubilities were reported for hydrocortisone after 24 and $72 \mathrm{~h}$ equilibration times. In a recent paper, ${ }^{18}$ the solubility of four drugs including budesonide in a number of monosolvents was reported.

In this work, the experimental solubility of budesonide, hydrocortisone, and prednisolone in ethanol + water mixtures at 298.2 $\mathrm{K}$ are reported. To our knowledge, there is no published solubility data for these drugs in ethanol + water mixtures. In addition, we illustrate the applicability of the Jouyban-Acree model to the measured drug solubility data, and the prediction capability of the above-mentioned trained models for predicting the solubility of drugs in ethanol + water mixtures was investigated.

\section{Experimental Method}

Materials. Budesonide (> $99 \%$ in mass fraction) was purchased from Industriale Chimica s.r.l., Italy. Hydrocortisone (98 \% in mass fraction) and prednisolone (99\% in mass fraction) were purchased from Sigma-Aldrich, U.S.A. Absolute ethanol was purchased from Fisher Scientific Ltd., Loughborough, U.K. Distilled water was obtained from Purelab, ELGA, U.K.

Apparatus and Procedures. The binary solvent mixtures were prepared by mixing the appropriate volumes of the solvents with the accuracy of 0.001 volume fraction. The solubility of corticosteroids in ethanol + water mixtures was determined by equilibrating

\begin{tabular}{|c|c|c|c|c|c|c|c|c|c|c|}
\hline \multirow[b]{2}{*}{ drug } & \multicolumn{5}{|c|}{ computed } & \multicolumn{5}{|c|}{ experimental } \\
\hline & $E$ & $S$ & $A$ & $B$ & $V$ & $E$ & $S$ & $A$ & $B$ & $V$ \\
\hline budesonide & 2.33 & 3.23 & 0.48 & 2.16 & 3.27 & $a$ & $a$ & $a$ & $a$ & $a$ \\
\hline hydrocortisone & 2.04 & 2.92 & 0.73 & 1.90 & 2.80 & 2.06 & 3.16 & 0.72 & 1.98 & 2.80 \\
\hline prednisolone & 2.19 & 3.02 & 0.73 & 1.97 & 2.76 & 2.19 & 3.26 & 0.72 & 2.00 & 2.75 \\
\hline
\end{tabular}
excess amounts of the solids at $298.2 \mathrm{~K}$ using a shaker (Grant Instruments, Cambridge Ltd., England) placed in an incubator equipped with a temperature-controlling system maintained constant to within $\pm 0.2 \mathrm{~K}$. After a sufficient length of time $(>24 \mathrm{~h})$, the saturated solutions of the drugs were filtered using hydrophilic Durapore filters $(0.45 \mu \mathrm{m}$, Milipore, Ireland $)$, diluted with ethanol, and then assayed spectrophotometrically (V-530 UV-vis spectrophotometer, Jasco, Japan) at wavelengths of (240, 247, and 247) $\mathrm{nm}$ for budesonide, hydrocortisone, and prednisolone, respectively. The preliminary investigations showed that the filter did not absorb the solutes through the filtration process. Concentrations of the diluted solutions were determined from the calibration curves. Details of calibration curves are shown in Table 3. Each experimental data point represents the average of at least three repetitive experiments with the measured $\mathrm{mol} \cdot \mathrm{L}^{-1}$ solubilities being reproducible to within $\pm 5.3 \%$. The densities of the saturated solutions were determined using a $10 \mathrm{~mL}$ density bottle (Technico, England).

Computational Methods. Equation 1 was fitted to the experimental solubility data of each drug, and the back-calculated

Table 1. Abraham Solute Parameters of the Drugs Computed by PharmaAlgorithm 9 and the Experimental Values ${ }^{15}$ 
solubilities were used to calculate the accuracy of the fit. The solubilities of three drugs were predicted using eqs 2 to 5 employing the experimental solubilities of drugs in ethanol and water at 298.2 $\mathrm{K}$. The mean relative deviation (MRD) was used to check the accuracy of the predictions using

$$
\mathrm{MRD}=\frac{\sum\left\{\frac{\left|\left(C_{m, T}^{\mathrm{Sat}}\right)_{\mathrm{pred}}-\left(C_{m, T}^{\mathrm{Sat}}\right)\right|}{\left(C_{m, T}^{\mathrm{Sat}}\right)}\right\}}{N}
$$

where $N$ is the number of data points in each set. Goodness of fit to each method was also shown by plotting the predicted and experimental solubilities of the drugs against the volume fraction of ethanol.

\section{Results and Discussion}

Table 4 lists the experimental solubilities of budesonide, hydrocortisone, and prednisolone in ethanol + water mixtures

Table 2. Abraham Solvent Coefficients Employed in This Work ${ }^{10}$

\begin{tabular}{lrrrrrr}
\hline solvent & \multicolumn{1}{c}{$c$} & $e$ & \multicolumn{1}{c}{$s$} & $a$ & \multicolumn{1}{c}{$b$} & \multicolumn{1}{c}{$v$} \\
\hline ethanol & 0.208 & 0.409 & -0.959 & 0.186 & -3.645 & 3.928 \\
water & -0.994 & 0.577 & 2.549 & 3.813 & 4.841 & -0.869
\end{tabular}

Table 3. Details of Calibration Curves of Drugs

\begin{tabular}{|c|c|c|c|c|c|}
\hline & $\lambda$ & $\varepsilon$ & $c$ & & \\
\hline drug & $\overline{\mathrm{nm}}$ & $\overline{\mathrm{L} \cdot \mathrm{mol}^{-1} \cdot \mathrm{cm}^{-1}}$ & $\mathrm{~mol} \cdot \mathrm{L}^{-1}$ & correlation coefficient & calibration curve ( $A$ : absorbance) \\
\hline budesonide & 240 & 14724 to 15542 & $2.32 \cdot 10^{-6}$ to $4.65 \cdot 10^{-5}$ & 0.998 & $c=6 \cdot 10^{-5} A+2 \cdot 10^{-7}$ \\
\hline hydrocortisone & 247 & 15227 to 15517 & $1.38 \cdot 10^{-5}$ to $5.51 \cdot 10^{-5}$ & 0.999 & $c=7 \cdot 10^{-5} A+4 \cdot 10^{-7}$ \\
\hline prednisolone & 247 & 14417 to 16580 & $6.93 \cdot 10^{-6}$ to $5.54 \cdot 10^{-5}$ & 0.999 & $c=6 \cdot 10^{-5} A+2 \cdot 10^{-6}$ \\
\hline
\end{tabular}

Table 4. Experimental $\mathrm{mol} \cdot \mathrm{L}^{-1}$ Solubilities of Budesonide, Hydrocortisone, and Prednisolone in Different Volume Fractions of Ethanol $\left(\varphi_{1}\right)$ in Ethanol (1) + Water (2) Mixtures at 298.2 K and Density $\rho$ of the Saturated Solutions

\begin{tabular}{|c|c|c|c|c|c|c|}
\hline \multirow[b]{2}{*}{$\varphi_{1}$} & \multirow[b]{2}{*}{ Budesonide } & \multirow{2}{*}{$\frac{C_{m, T}^{\text {Sat }}}{\text { Hydrocortisone }}$} & \multirow[b]{2}{*}{ Prednisolone } & \multirow[b]{2}{*}{ Budesonide } & $\rho^{a} / \mathrm{g} \cdot \mathrm{cm}^{-3}$ & \multirow[b]{2}{*}{ Prednisolone } \\
\hline & & & & & Hydrocortisone & \\
\hline 0.000 & 0.000065 & 0.000860 & 0.000756 & 1.003 & 1.005 & 1.005 \\
\hline 0.100 & 0.000186 & 0.001959 & 0.001720 & 0.995 & 0.990 & 0.995 \\
\hline 0.200 & 0.000472 & 0.003090 & 0.003607 & 0.984 & 0.985 & 0.985 \\
\hline 0.300 & 0.001394 & 0.006400 & 0.008712 & 0.969 & 0.968 & 0.967 \\
\hline 0.400 & 0.003298 & 0.014897 & 0.014510 & 0.954 & 0.955 & 0.951 \\
\hline 0.500 & 0.010917 & 0.022538 & 0.026634 & 0.940 & 0.934 & 0.933 \\
\hline 0.600 & 0.019743 & 0.040552 & 0.060482 & 0.910 & 0.918 & 0.917 \\
\hline 0.700 & 0.041461 & 0.062759 & 0.089613 & 0.888 & 0.890 & 0.893 \\
\hline 0.800 & 0.072004 & 0.078345 & 0.113750 & 0.870 & 0.865 & 0.872 \\
\hline 0.900 & 0.081295 & 0.064317 & 0.105427 & 0.843 & 0.830 & 0.843 \\
\hline 1.000 & 0.062713 & 0.040552 & 0.067418 & 0.799 & 0.792 & 0.803 \\
\hline
\end{tabular}

${ }^{a}$ Results of a single determination.

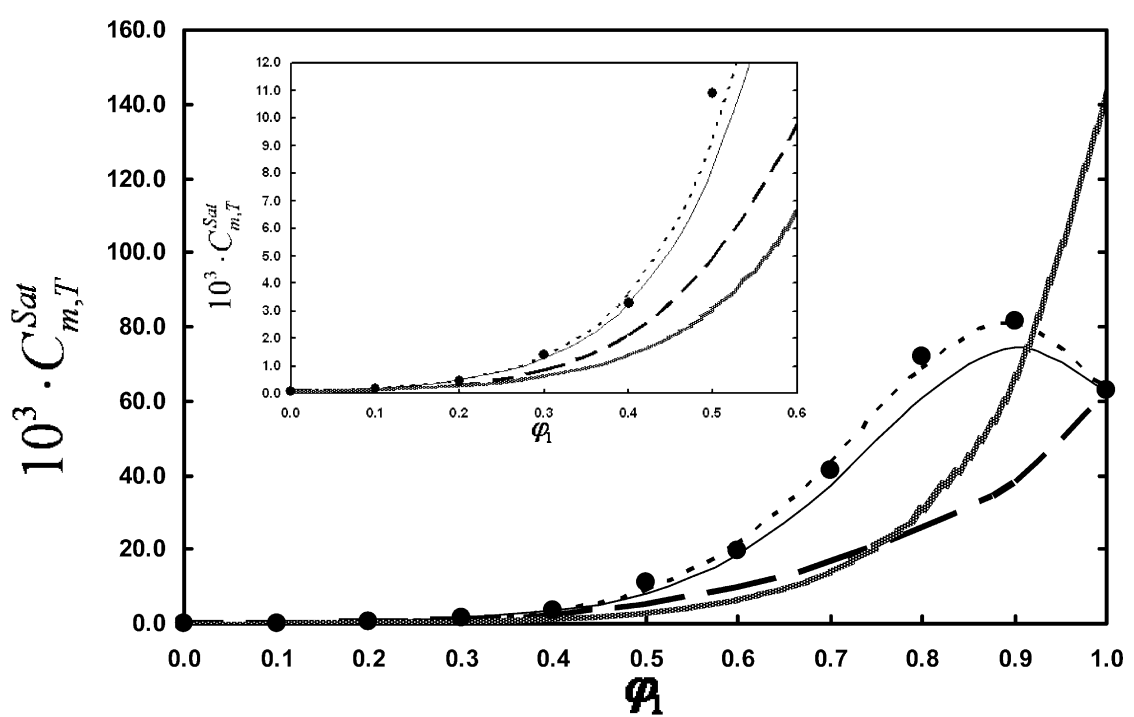

Figure 1. $\mathrm{mol} \cdot \mathrm{L}^{-1}$ solubility of budesonide $\left(C_{m, T}^{\mathrm{Sat}}\right)$ at various volume fractions of ethanol $\left(\varphi_{1}\right)$ in binary solvent mixtures; $\bullet$, experimental; and the predicted solubilities using: short-dashed line, eq 1 ; solid line, eq 2 ; long-dashed line, eq 4 ; gray patterned line, eq 5 . Inset presents the solubilities in a different scale at $\varphi_{1}<0.6$. 


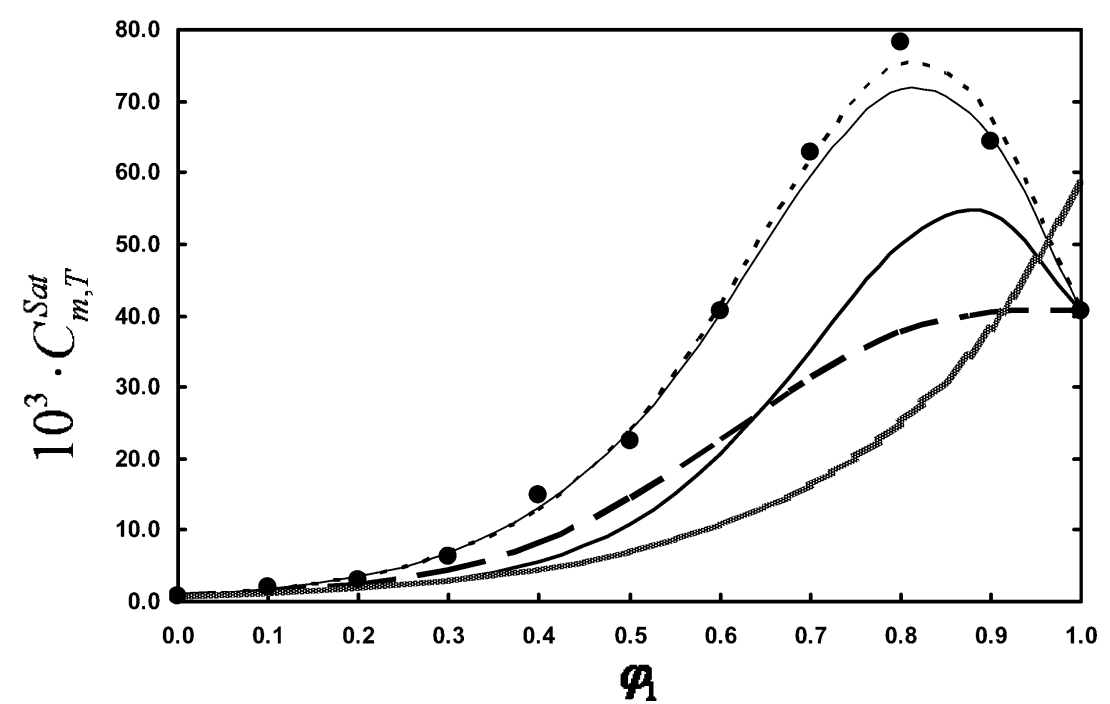

Figure 2. $\mathrm{mol} \cdot \mathrm{L}^{-1}$ solubility of hydrocortisone $\left(C_{m, T}^{\mathrm{Sat}}\right)$ at various volume fractions of ethanol $\left(\varphi_{1}\right)$ in binary solvent mixtures; $\bullet$, experimental; and the predicted solubilities using: short-dashed line, eq 1; solid line, eq 2; bold solid line, eq 3; long-dashed line, eq 4; gray patterned line, eq 5.

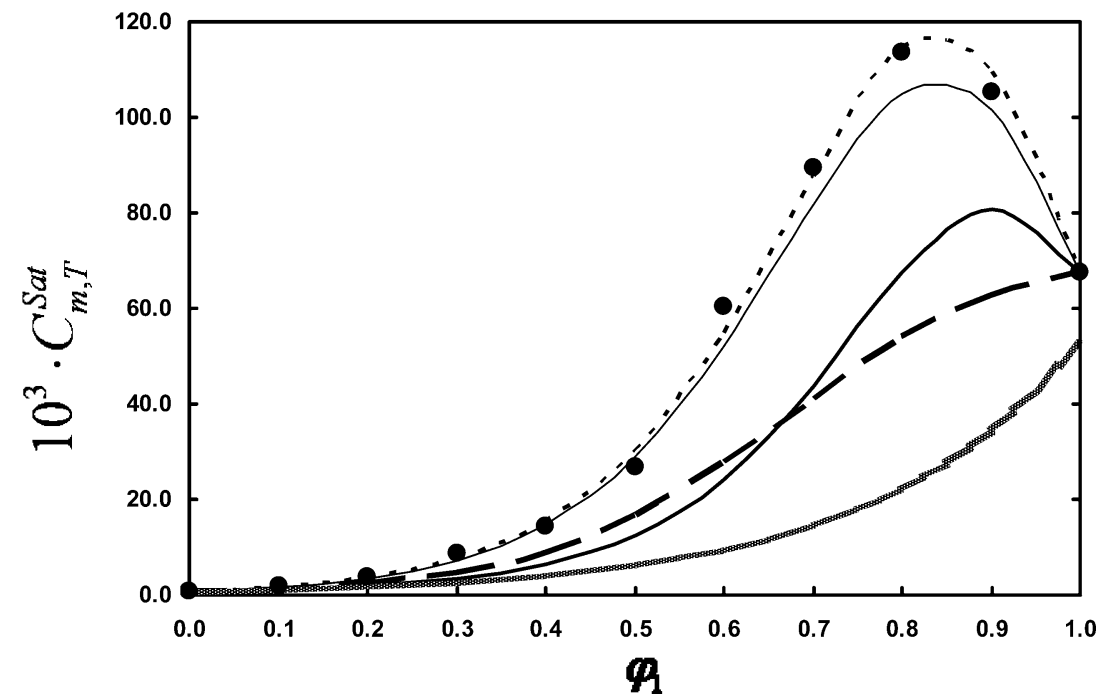

Figure 3. $\mathrm{mol} \cdot \mathrm{L}^{-1}$ solubility of prednisolone $\left(C_{m, T}^{\text {Sat }}\right)$ at various volume fractions of ethanol $\left(\varphi_{1}\right)$ in binary solvent mixtures; $\boldsymbol{\bullet}$, experimental; and the predicted solubilities using: short-dashed line, eq 1; solid line, eq 2; bold solid line, eq 3; long-dashed line, eq 4; gray patterned line, eq 5.

Table 5. Numerical Values of the Adjusted Parameters of Equation 1 for Each Solute and the MRD for the Predicted Solubilities of Drugs in Ethanol (1) + Water (2) Mixtures Using Various Equations and Their Overall Values

\begin{tabular}{lccccccccccc}
\hline & & & & \multicolumn{5}{c}{$100 \cdot$ MRD } \\
\cline { 6 - 10 } \multicolumn{1}{c}{ drug } & $J_{0}$ & $J_{1}$ & $J_{2}$ & eq 1 & eq 2 & eq 3 & eq 4 & eq 5 \\
\hline budesonide & 787.695 & 553.250 & 198.335 & 4.9 & 7.2 & & 38.7 & 52.6 \\
hydrocortisone & 727.992 & 520.867 & 230.505 & 5.5 & 5.7 & 36.2 & 33.0 & 50.7 \\
prednisolone & 743.670 & 492.221 & 324.069 & 4.8 & 6.4 & 39.2 & 36.1 & 58.1 \\
overall & & & & 5.1 & 6.4 & 37.7 & 35.9 & 53.8
\end{tabular}

aqueous solubility, the reported data $\left(0.001085 \mathrm{~mol} \cdot \mathrm{L}^{-1}\right),{ }^{24}$ and the solubility determined at room temperature $\left(22{ }^{\circ} \mathrm{C}\right.$ to $\left.24{ }^{\circ} \mathrm{C}\right)$ which was higher than $\left(0.00106 \mathrm{~mol} \cdot \mathrm{L}^{-1}\right)^{20}$ our data.

The predicted solubilities by eqs 1 to 5 and the corresponding experimental values against the volume fraction of ethanol in the binary mixtures were plotted in Figures 1, 2, and 3. As shown in the figures, the Jouyban-Acree model fits very well to the experimental solubility data of drugs at all composition ranges of ethanol. This finding is also supported by small MRD values of the back-calculated and experimental solubility data. The main limitation of eq 1 is that it should be trained for each drug employing a minimum number of experimental data in binary solvents; however, when the constants for each system were calculated, the model could be used to predict the solubility at other solvent compositions ${ }^{25}$ or other temperatures, ${ }^{6}$ and the expected prediction MRD is less than $16 \%$. $^{6,25}$

The predictive versions of the Jouyban-Acree model, that is, eqs 2 to 4, predict the solubility values with reasonable MRD values. The predicted solubilities were compared with the corresponding experimental data, and MRD values were computed and listed in Table 5. The prediction procedure using eq 2 is straightforward and could be preferred in solubility predictions in ethanol + water mixtures at various temperatures. However, it is only applicable for ethanol + water mixtures. As noticed above, eqs 3 and 4 are generally trained for predicting the solubility of drugs in cosolvent + water at various temperatures and require the Abraham solvent coefficients. These coefficients are not available for common pharmaceutical cosolvents including polyethylene glycols, $\mathrm{N}$-methyl-2-pyrrolidone, propylene glycol, and so forth. Generally, the overall MRDs observed in these predictions show that the Jouyban-Acree model is robust and could be used for prediction purposes with reasonable accuracy. A very simple and well-established 
$\log$-linear model of Yalkowsky (eq 5) is also able to predict the solubility of drugs with relatively higher MRDs as listed in Table 5 .

\section{Literature Cited}

(1) Jouyban, A. Handbook of Solubility Data for Pharmaceuticals; CRC Press: Boca Raton, FL, 2009.

(2) Jouyban, A. Review of the Cosolvency Models for Predicting Solubility of Drugs in Water-Cosolvent Mixtures. J. Pharm. Pharm. Sci. 2008, $11,32-58$.

(3) Acree, W. E., Jr. Mathematical Representation of Thermodynamic Properties. Part II. Derivation of the Combined Nearly Ideal Binary Solvent (NIBS)/Redlich-Kister Mathematical Representation from a Two-Body and Three-Body Interactional Mixing Model. Thermochim. Acta 1992, 198, 71-79.

(4) Jouyban, A.; Acree, W. E., Jr. In Silico Prediction of Drug Solubility in Water - Ethanol Mixtures Using Jouyban-Acree Model. J. Pharm. Pharm. Sci. 2006, 9, 262-269.

(5) Shayanfar, A.; Fakhree, M. A. A.; Acree, W. E., Jr.; Jouyban, A. Solubility of Lamotrigine, Diazepam, and Clonazepam in Ethanol + Water Mixtures at 298.15 K. J. Chem. Eng. Data 2009, 54, $1107-$ 1109.

(6) Jouyban, A.; Acree, W. E., Jr. Comments on "Solubility of Ethyl Maltol in Aqueous Ethanol Mixtures". J. Chem. Eng. Data 2009, 54, 11681170.

(7) Jouyban, A.; Shokri, J.; Barzegar-Jalali, M.; Hassanzadeh, D.; Acree, W. E., Jr.; Ghafourian, T.; Nokhodchi, A. Solubility of Chlordiazepoxide, Diazepam, and Lamotrigine in Ethanol + Water Mixtures at 298.2 K. J. Chem. Eng. Data 2009, 54, 2142-2145.

(8) Jouyban, A.; Soltanpour, S.; Soltani, S.; Chan, H. K.; Acree, W. E., Jr. Solubility Prediction of Drugs in Water-Cosolvent Mixtures Using Abraham Solvation Parameters. J. Pharm. Pharm. Sci. 2007, 10, 294 308.

(9) ADME Boxes, Version 4.0; Pharma Algorithms: Toronto, 2008.

(10) Stovall, D. M.; Acree, W. E., Jr.; Abraham, M. H. Solubility of 9-Fluorenone, Thianthrene and Xanthene in Organic Solvents. Fluid Phase Equilib. 2005, 232, 113-121.

(11) Jouyban, A.; Soltanpour, S.; Soltani, S.; Tamizi, E.; Fakhree, M. A. A.; Acree, W. E., Jr. Prediction of Drug Solubility in Mixed Solvents Using Computed Abraham Parameters. J. Mol. Liq. 2009, 146, 82 88.

(12) Yalkowsky, S. H.; Roseman, T. Solubilization of Drugs by Cosolvents; Marcel Dekker: New York, 1981; pp 91-134.

(13) Li, A.; Yalkowsky, S. H. Predicting Cosolvency. 1. Solubility Ratio and Solute log Kow. Ind. Eng. Chem. Res. 1998, 37, 4470-4475.
(14) Lin, H.; Yoo, J. W.; Roh, H. J.; Lee, M. K.; Chung, S. J.; Shim, C. K.; Kim, D. D. Transport of Anti-Allergic Drugs Across the Passage Cultured Human Nasal Epithelial Cell Monolayer. Eur. J. Pharm. Sci. 2005, 26, 203-210.

(15) Zhao, Y. H.; Le, J.; Abraham, M. H.; Hersey, A.; Eddershaw, P. J.; Luscombe, C. N.; Boutina, D.; Beck, G.; Sherborne, B.; Cooper, I.; Platts, J. A. Evaluation of Human Intestinal Absorption Data and Subsequent Derivation of a Quantitative Structure - Activity Relationship (QSAR) with the Abraham Descriptors. J. Pharm. Sci. 2001, 90, 749-784.

(16) Hagen, T. A.; Flynn, G. L. Solubility of Hydrocortisone in Organic and Aqueous Media: Evidence for Regular Solution Behavior in Apolar Solvents. J. Pharm. Sci. 1983, 72, 409-414.

(17) Bergström, C. A. S.; Norinder, U.; Luthman, K.; Artursson, P. Experimental and Computational Screening Models for Prediction of Aqueous Drug Solubility. Pharm. Res. 2002, 19, 182-188.

(18) Mota, F. L.; Carneiro, A. P.; Queimada, A. J.; Pinho, S. P.; Macedo, E. A. Temperatura and Solvent Effects in the Solubility of Some Pharmaceutical Compounds: Measurements and Modeling. Eur. J. Pharm. Sci. 2009, 37, 499-507.

(19) Kabasakalian, P.; Britt, E.; Yudis, M. D. Solubility of Some Steroids in Water. J. Pharm. Sci. 1966, 55, 642.

(20) Loftsson, T.; Hreinsdoóttir, D. Determination of Aqueous Solubility by Heating and Equilibration: A technical Note. AAPS PharmSciTech 2006, 7, Article no. 4.

(21) Stella, V. J.; Lee, H. K.; Thompson, D. O. The Effect of SBE4- $\beta$-CD on i.m. Prednisolone Pharmacokinetics and Tissue Damage in Rabbits: Comparison to a Co-solvent Solution and a Water-Soluble Prodrug. Int. J. Pharm. 1995, 120, 197-204.

(22) Kühne, R.; Ebert, R. U.; Kleint, F.; Schmidt, G.; Schüürmann, G. Group Contribution Methods to Estimate Water Solubility of Organic Chemicals. Chemosphere 1995, 30, 2061-2077.

(23) Zhao, L.; Orton, E.; Vemuri, N. M. Predicting Solubility in Multiple Nonpolar Drugs-Cyclodextrin System. J. Pharm. Sci. 2002, 91, 23012306.

(24) Larsen, K. L.; Aachmann, F. L.; Wimmer, R.; Stella, V. J.; Kjølner, U. M. Phase Solubility and Structure of the Inclusion Complexes of Prednisolone and $6 \alpha$-Methyl Prednisolone with Various Cyclodextrins. J. Pharm. Sci. 2005, 94, 507-515.

(25) Jouyban-Gharamaleki, A.; York, P.; Hanna, M.; Clark, B. J. Solubility Prediction of Salmeterol Xinafoate in Water-Dioxane Mixtures. Int. J. Pharm. 2001, 216, 33-41.

Received for review April 23, 2009. Accepted August 25, 2009.

JE900376R 